\title{
DESENVOLVIMENTO DO BEM VIVER JUNTO AOS POVOS TRADICIONAIS
}

\author{
DEVELOPMENT OF THE WELL LIVING WITH TRADITIONAL PEOPLE
}

\author{
Roberto Gilonna Júnior ${ }^{1}$
}

José Eurico Ramos de Souza ${ }^{2}$

\begin{abstract}
RESUMO: Neste Trabalho de Conclusão de Curso de Especialização em Desenvolvimento, Etnicidade e Políticas Públicas, objetivou-se analisar os indicadores de Bem-Estar Humano sob a perspectiva do Bem Viver dos povos tradicionais. Para tanto, a pesquisa foi de caráter qualitativo exploratório, com a utilização do método de revisão bibliográfica dispondo de artigos científicos, livros e e-books que nos possibilitam subsídios para a relação entre desenvolvimento e bem viver. Faz uma leitura das alternativas e qual horizonte se evidencia. Uma amostra disso está nos Indicadores de Bem Viver para os Povos Tradicionais, apoiados nos sobrenomes dados ao desenvolvimento e índices, interligando-se às necessidades axiológicas com as necessidades existenciais. Os resultados apontam preocupações compartilhadas pela justiça social e pela igualdade social quando do cruzamento das necessidades axiológicas e existenciais, para a construção do pensamento em relação ao Bem Viver dos povos tradicionais. Esse trabalho sugere reflexões sobre as leis naturais e leis físico-humanas que sofrem alterações numa tentativa de trazer uma relação de bem viver mais saudável e amigável aos povos tradicionais.
\end{abstract}

Palavras-chave:: BemViver. Cultura. Desenvolvimento. Etnia. Tradicionais.

ABSTRACT: In this Work of Conclusion of the Specialization Course in Development, Ethnicity and Public Policies, the objective was to analyze the indicators of Human Welfare from the

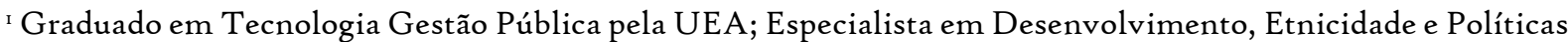
Públicas - IFAM; Especialista em Docência do Ensino Superior; Especialista em Educação à Distância - UNIP; Mestrando em Ciências da Educação; Experiência como Professor Tutor; Professor/Consultor nível II UNIP; Experiência em criação e treinamentos para Gestão de Associações e Cooperativas; Pesquisador em Acessibilidade e Inclusão no Grupo Multidisciplinar de Estudos e Pesquisas sobre Inclusão e Cidadania IFAM; Pesquisador em Políticas Públicas atuando no tema sobre Políticas Públicas para Pessoas com Deficiência, Povos Tradicionais, Ribeirinhos, Quilombolas em Empregabilidade, Trabalho, Cooperativismo, Associativismo; Atuou como professor nas disciplinas de Metodologia do Trabalho Científico (MTC), Gestão em Saúde com Ênfase em Saúde Pública em Pós-graduação na CELCON- Consultoria em Educação e Treinamentos; atualmente é Professor Universitário - UNIP/Ramos - Manaus nas disciplinas de História da Educação, Educação de Jovens e Adultos (Fundamentos e Metodologias), Ciências Sociais, Economia e Mercado, História do Pensamento Filosófico, Recursos Materiais e Patrimoniais. E-mail: robertogilonna4@gmail.com.

${ }^{2}$ Doutor em Educação pela Universidade Federal do Amazonas (2018), Mestre em Educação pela Universidade Federal do Amazonas (20II), Pós-graduação lato sensu em Estatística e Matemática pela Universidade Federal de Lavras (200I), graduado em Licenciatura Plena em Matemática pela Universidade Federal do Amazonas (1992). Professor de Ensino Básico, Técnico e Tecnológico do Instituto Federal de Educação Ciências e Tecnologia do Amazonas - Campus Manaus Zona Leste. Tendo exercido vários cargos de direção como: diretor do departamento de ensino e diretor geral substituto. Tem experiência na área de Educação, com ênfase em Educação Profissional e ensino de Matemática e Estatística Básica, atuando principalmente nos seguintes temas: Estado e Políticas de Desenvolvimento do Campo, políticas públicas para educação profissional, educação profissional, gestão escolar, currículo e avaliação, metodologia do ensino da matemática.E-mail: eurico.souza@ifam.edu.br. 
perspective of the Well Living of traditional peoples. Therefore, the research was qualitative exploratory, using the method of bibliographic review with scientific articles, books and e-books that allow us to support the relationship between development and good living. Do a reading of the alternatives and which horizon is evident. A sample of this is in the Well-Being Indicators for Traditional Peoples, supported by the surnames given to development and indices, linking axiological needs with existential needs. The results point to concerns shared by social justice and social equality when the axiological and existential needs intersect, for the construction of the thinking regarding the Good Living of traditional peoples. This work suggests reflections on the natural laws and physical-human laws that are changing in an attempt to bring a healthier and more friendly living relationship to traditional peoples.

Keywords: Good Living. Culture. Development. Ethnicity. Traditional.

\section{INTRODUÇÃO}

Com o tema desenvolvimento do bem viver junto aos povos tradicionais, este trabalho de conclusão de curso faz uma análise reflexiva junto aos indicadores sociais, integrando as necessidades axiológicas com as necessidades existenciais.

Para uma melhor compreensão adota-se neste o termo Bem Viver por entender que é um modo de vida onde os Guaranis chamam tekón, isto é, modo ser e estar, é um sistema, é costume, é um habitus, abrindo-se mão de terminologias paralelas como Viver Melhor e Bem-Estar por considerar que cada nomenclatura tem seu próprio conceito.

O objetivo geral foi de verificar de que forma o desenvolvimento pode influenciar no bem

viver dos povos tradicionais. Mas para ter uma resposta mais eficaz a esse objetivo geral, traçou-se os seguintes objetivos específicos: analisar os conceitos e a história da motivação; entender a organização e seus desafios aos povos tradicionais; e verificar a importância da proposta de bem viver. Os métodos de estudos bibliográficos tiveram como tipo de pesquisa: exploratória, descritiva e explicativa.

Além destas questões que geraram a oportunidade do trabalho de conclusão, existe a motivação pessoal do autor, admirador incontestável de todo o rico material cultural enraizado na história. E como qualquer pesquisa, ela depende também de uma base bibliográfica, em artigos científicos, livros e e-books que nos possibilitam subsídios para o conhecimento.

Portanto, nas seções do trabalho verificam-se primeiramente os conceitos sobre o bem viver; segundo o desenvolvimento que vai do entusiasmo à frustração verificando os sobrenomes de desenvolvimento humano, desenvolvimento em escala humana e desenvolvimento sustentável, os sobrenomes dados aos índices como índice de capacidade básica, índice do planeta feliz e índice da felicidade interna; bem viver como alternativa ao desenvolvimento; horizonte estratégico; o viver melhor ou bem viver?

\footnotetext{
${ }^{3}$ http://www.raiz.org.br/o-bem-viver-guarani-teko-pora. Acesso em 21 set 2019.
} 
Além do interesse pela temática, o estudo justifica-se pelas seguintes razões: no campo da gestão pública - pela contribuição para compreensão na formulação de políticas públicas; no campo acadêmico - o trabalho se reveste de importância pelas contribuições que trará para professores, pesquisadores e estudantes em geral; no campo social o trabalho justifica-se pelo fato que o desenvolvimento do bem viver é um fator essencial aos povos tradicionais.

Ao concluir o trabalho faz reflexões sobre a existência de leis naturais e leis físico-humanas que passam por alterações e renovações nas relações de bem viver para que se torne mais saudável e amigável junto aos povos tradicionais, tencionando analisar, entender e verificar os fatores que levam ao estudo do desenvolvimento do bem viver junto aos povos tradicionais.

\section{Conceito de bem viver}

Os discursos voltados ao desenvolvimento humano e ao bem-estar ou bem viver da sociedade, tornam-se multilinear a partir da diversidade das culturas expressas nas Constituições de países latino-americanos, como Colômbia, Equador e Bolívia. Neste cenário, destaca-se a contribuição da Organização das Nações Unidas (ONU) em documentos publicados, apresentados e debatidos sobre o tema destacando a necessidade,

[...] de respeitar e promover os direitos intrínsecos dos povos indígenas, que derivam de suas necessidades políticas, econômicas e sociais e de suas culturas, de suas tradições espirituais, de sua história e de sua concepção de vida, especialmente dos direitos a suas terras, territórios e recursos (ONU, 2007, p. 4).

Neste sentido, o Bem Viver segundo Vanhulst e Beling (2014) aparece como um discurso no final de 1990, impulsionado por três atores importantes: movimentos sociais latino-americanos da época (particularmente o movimento indígena contra o neoliberalismo final do século XX); convergência entre os referidos movimentos e as ideologias de determinados movimentos globais (especialmente antiglobalização e movimentos ambientais); e desencanto generalizado com a ideia de desenvolvimento.

Entretanto, o tema do Bem Viver, expõe críticas à teoria clássica do modelo de desenvolvimento ocidental e apresenta alternativas ao desenvolvimento embasadas nas tradições indígenas, repousando seu pensamento na lógica de convivência dos grupos sociais (YAMPARA, 1995).

De acordo com Santos (2019) bem viver é experimentado por centenas de comunidades e povos indígenas na América Latina, inspirando a repensar valores e práticas da cultura contemporânea.

As concepções do Bem Viver também estão presentes nas cosmovisões de outros povos indígenas da região andina e amazônica, mas com termos e traduções ligeiramente distintas em virtude das diferenças próprias de cada cultura. 
Nestas experiências resultam da compreensão simplista do mundo, concomitante da dominação da natureza pelo homem, para o entendimento sistêmico e complexo da dinâmica socioambiental. A cosmovisão ocorre no mundo da vida, nas comunidades, nos povoados, nas organizações, onde os problemas e as soluções acontecem e raramente são qualificados, tratando-se de uma teoria pensada, a partir do desenvolvimento das experimentações e da complexidade do cotidiano (SACHS, 1986).

Como proposta global, o Bem Viver se coaduna na harmonia com a natureza, mutualidade, relacionamento, completividade e auxílios entre comunidade e indivíduos, com conhecimento dos valores de uso do Bem Viver em uma ideia de construção, livre do paradigma do preconceito, abordando valores, experiências e práticas de algumas reflexões em um contexto universal.

De acordo com Acosta (2016) o Bem Viver questiona o conceito eurocêntrico por enfrentar a colonização do poder, sem minimizar a contribuição indígena, como fonte inspiradora. Compreende-se que há, gradualmente, um início do impedimento no estilo de vida predominante.

A evidência desse fato está em que,

A difusão de certos padrões de consumo, em uma pirueta de absoluta perversidade, se infiltra no imaginário coletivo, inclusive no de amplos grupos humanos que não possuem condições econômicas para acessá-los, mantendo-os prisioneiros de um desejo permanente. As mensagens consumistas penetram por todas as brechas da sociedade (ACOSTA, 2016, p.35).

Subtrai-se que, a maioria das pessoas só trabalham e produzem com a expectativa de que o produto seja consumido, vivendo insatisfeitas em suas necessidades permanentemente. Amarradas ao consumo de maneira irracional, criando tensões levadas pelas desigualdades sociais. Os avanços tecnológicos só aceleraram esse processo de perturbação no desenvolvimento desse Bem Viver, acelerando o círculo perverso da produção e a apetência cada vez mais destrutiva. Não importa apenas com isso o destino, mas também o caminho pelo qual será assegurado o desenvolvimento à sobrevivência da humanidade.

Segundo Cruz (2015) no Amazonas, "expressão Bem Viver vem sendo utilizada há alguns anos pelas lideranças Baniwa na elaboração de projetos pautados na noção de desenvolvimento sustentável e de etnodesenvolvimeto".

Esse é também posicionamento de Souza (2018) quando retrata a proposta de desenvolvimento para a região do Rio Negro partindo de uma discussão como parte da valorização na diversidade cultural, tradicional e não-índios.

\section{O desenvolvimento: do entusiasmo à frustração}

O desenvolvimento nasce na década de 1920 a partir de uma ruína de paisagens, cujos alicerces antagônicos são de engano e desilusão, vitórias e fracassos, e tendo os crimes como 
companheiros permanentes. Além disso, aparece com as múltiplas formas de interpretação, assumindo-se inclusive como prenome de "índice". Ao final, as esperanças e os desejos que lhe deram sustento, então esgotados, o desenvolvimento ficou obsoleto. Daí a análise partir para os sobrenomes de desenvolvimento e índices.

\section{Desenvolvimento e seus sobrenomes}

Para Acosta (2016) o fracasso da teoria geral do desenvolvimento a partir de 1960 trouxe-nos uma nova forma de pensar ferramentas e indicadores conceituais, especialmente para obter-se visões críticas ao terreno do desenvolvimento econômico, social, e mais tarde, ambiental. Ao se pensar o Bem Viver, precisa-se interagir sob:

a) Desenvolvimento humano

O economista indiano Sen (2018) nos anos de 1990 propõe à Organização das Nações Unidas (ONU) a criação do Índice de Desenvolvimento Humano, como uma maneira mais completa para entendimento da ampliação das oportunidades e das capacidades das pessoas a elementos dignos de valorização: educação, saúde, igualdade social, preservação da natureza, igualdade de gênero, respeito aos povos tradicionais.

b) Desenvolvimento em escala humana

Max-Neef; Elizalde; Hopenhayn (1994) caracterizam o desenvolvimento em escala humana através de uma matriz que engloba nove necessidades axiológicas: subsistência, proteção, afeto, compreensão, participação, criação, diversão, identidade e liberdade. Além de quatro necessidades existenciais: ser, ter, fazer, estar. Estas necessidades dispostas em colunas refletem o seguinte: A coluna SER registra atributos, pessoais ou coletivos; A coluna de TER registra instituições, padrões, mecanismos, ferramentas (não em sentido material), leis, etc., que eles podem ser expressos em uma ou mais palavras; A coluna FAZER registra ações, pessoais ou coletivas que podem ser expressas; A coluna ESTAR registra espaços e ambientes conforme quadro a seguir.

Quadro I - Matriz de necessidades e satisfações

\begin{tabular}{|l|c|c|c|c|}
\hline $\begin{array}{c}\text { Necessidades } \\
\text { Existenciais }\end{array}$ & TER & SER & FAZER & ESTAR \\
\hline $\begin{array}{l}\text { Axiossidades } \\
\text { Subsistência }\end{array}$ & $\begin{array}{c}\text { Saúde física. } \\
\text { saúde mental, } \\
\text { equilíbrio, } \\
\text { solidariedade }\end{array}$ & $\begin{array}{c}\text { Alimento } \\
\text { Vestimentas, } \\
\text { roupas } \\
\text { trabalho }\end{array}$ & $\begin{array}{c}\text { Comer, } \\
\text { Procriar, } \\
\text { Descansar, } \\
\text { Trabalho }\end{array}$ & $\begin{array}{c}\text { Ambiente de } \\
\text { vida, } \\
\text { Ambiente } \\
\text { social }\end{array}$ \\
\hline
\end{tabular}




\begin{tabular}{|c|c|c|c|c|}
\hline Proteção & $\begin{array}{c}\text { Cuidado } \\
\text { adaptabilidade, } \\
\text { autonomia, } \\
\text { equilíbrio, } \\
\text { solidariedade }\end{array}$ & $\begin{array}{c}\text { Sistemas de } \\
\text { seguro, poupança, } \\
\text { Segurança social, } \\
\text { sistemas de } \\
\text { saúde... }\end{array}$ & $\begin{array}{l}\text { Cooperar } \\
\text { impedir, } \\
\text { planejar, } \\
\text { cuidar } \\
\text { curar... }\end{array}$ & $\begin{array}{l}\text { Contorno da } \\
\text { vida, } \\
\text { esboço social, } \\
\text { moradia }\end{array}$ \\
\hline Afeto & $\begin{array}{l}\text { Autoestima, } \\
\text { solidariedade } \\
\text { respeito, } \\
\text { tolerância, } \\
\text { generosidade, } \\
\text { receptividade... }\end{array}$ & $\begin{array}{c}\text { Amizades, } \\
\text { casais } \\
\text { família, animais } \\
\text { doméstico } \\
\text { plantas, } \\
\text { jardins }\end{array}$ & $\begin{array}{l}\text { Fazer amor, } \\
\text { carícia } \\
\text { emoções } \\
\text { compartilhar, } \\
\text { cuidar, }\end{array}$ & $\begin{array}{l}\text { Privacidade, } \\
\text { Privacidade em } \\
\text { casa, } \\
\text { espaços para } \\
\text { encontro }\end{array}$ \\
\hline Compreensão & $\begin{array}{l}\text { Consciência } \\
\text { Crítica, } \\
\text { receptividade, } \\
\text { curiosidade, } \\
\text { espanto, } \\
\text { disciplina, } \\
\text { intuição... }\end{array}$ & $\begin{array}{l}\text { Literatura, } \\
\text { professores, } \\
\text { método, política } \\
\text { educacional, } \\
\text { política } \\
\text { comunicacional }\end{array}$ & $\begin{array}{l}\text { Investigação, } \\
\text { estudo, } \\
\text { experimento, } \\
\text { análise, } \\
\text { meditação, } \\
\text { interpretação }\end{array}$ & $\begin{array}{c}\text { Áreas } \\
\text { cognitivas, } \\
\text { escolas, } \\
\text { universidades, } \\
\text { academias } \\
\text { agrupamentos... }\end{array}$ \\
\hline Participação & $\begin{array}{l}\text { Adaptabilidade } \\
\text { receptividade, } \\
\text { solidariedade } \\
\text { disposição } \\
\text { convicção, } \\
\text { entrega... } \\
\end{array}$ & $\begin{array}{l}\text { Direitos, } \\
\text { responsabilidades, } \\
\text { obrigações, } \\
\text { atribuições, } \\
\text { emprego }\end{array}$ & $\begin{array}{l}\text { Afiliação, } \\
\text { cooperação, } \\
\text { propor, } \\
\text { compartilhar } \\
\text { discordar, } \\
\text { aceite... } \\
\end{array}$ & $\begin{array}{c}\text { Áreas de } \\
\text { Interação, } \\
\text { cooperativas, } \\
\text { associações, } \\
\text { igrejas, } \\
\text { comunidades... }\end{array}$ \\
\hline Criação & $\begin{array}{l}\text { Curiosidade, } \\
\text { receptividade, } \\
\text { imaginação } \\
\text { indiferença } \\
\text { humor } \\
\text { tranquilidade } \\
\text { sensualidade }\end{array}$ & $\begin{array}{c}\text { Jogos, } \\
\text { mostra } \\
\text { festas, calma }\end{array}$ & $\begin{array}{l}\text { Divagar, } \\
\text { seja abstraído, } \\
\text { sonhe, por } \\
\text { muito tempo, } \\
\text { fantasiar, } \\
\text { evocar, } \\
\text { relaxe... }\end{array}$ & $\begin{array}{l}\text { Privacidade, } \\
\text { espaços de } \\
\text { encontro, } \\
\text { tempo } \\
\text { livre, } \\
\text { ambientes, } \\
\text { paisagens }\end{array}$ \\
\hline Diversão & $\begin{array}{c}\text { Paixão, } \\
\text { vontade, } \\
\text { intuição } \\
\text { imaginação } \\
\text { audácia } \\
\text { racionalidade } \\
\text { autonomia... }\end{array}$ & $\begin{array}{l}\text { Habilidades, } \\
\text { Destrezas, } \\
\text { método, } \\
\text { trabalho }\end{array}$ & $\begin{array}{l}\text { Trabalhar, } \\
\text { inventar, } \\
\text { construir, } \\
\text { conceber, } \\
\text { compor, } \\
\text { design. } \\
\text { interpretar }\end{array}$ & $\begin{array}{c}\text { Áreas de } \\
\text { produção e } \\
\text { feedback, } \\
\text { oficinas, } \\
\text { agrupamentos, } \\
\text { audiência... }\end{array}$ \\
\hline Identidade & $\begin{array}{l}\text { Pertencendo, } \\
\text { consistência } \\
\text { diferença } \\
\text { autoestima, } \\
\text { assertividade }\end{array}$ & $\begin{array}{l}\text { Símbolos } \\
\text { idioma, } \\
\text { hábitos, } \\
\text { alfândega } \\
\text { grupos } \\
\text { de referência, } \\
\text { sexualidade } \\
\text { valores, }\end{array}$ & $\begin{array}{l}\text { Compromisso, } \\
\text { integrar, } \\
\text { confundir } \\
\text { definir, } \\
\text { conheçam-se, } \\
\text { reconheça-se } \\
\text { atualização, } \\
\text { crescer }\end{array}$ & $\begin{array}{l}\text { Socio-ritmos, } \\
\text { pequeno do } \\
\text { cotidiano, } \\
\text { áreas de } \\
\text { pertencer, } \\
\text { estágios } \\
\text { maturacional }\end{array}$ \\
\hline
\end{tabular}




\begin{tabular}{|c|c|c|c|c|}
\hline Liberdade & $\begin{array}{c}\text { Autonomia } \\
\text { autoestima, } \\
\text { vontade, } \\
\text { paixão, } \\
\text { assertividade, } \\
\text { abertura, } \\
\text { determinação... }\end{array}$ & $\begin{array}{c}\text { Igualdade de } \\
\text { direitos }\end{array}$ & $\begin{array}{c}\text { Discorde, } \\
\text { opte, } \\
\text { diferencie-se } \\
\text { conheçam-se, } \\
\text { assumir, } \\
\text { desobedecer, } \\
\text { meditar }\end{array}$ & $\begin{array}{l}\text { Plasticidade } \\
\text { espaço-tempo }\end{array}$ \\
\hline
\end{tabular}

Fonte: Max-Neef; Elizalde; Hopenhayn (1994, p. 58, 59 - Tradução: Roberto Gilonna Júnior).

c) Desenvolvimento sustentável

Conforme Cavalcanti (1994) o mundo, apesar do reconhecimento da importância do conceito de desenvolvimento sustentável, caminha certamente por rumos que desafiam qualquer noção de sustentabilidade, evidenciando aspectos da relação dos indígenas com o meio ambiente e mostra efeitos do contato interétnico com os europeus, finalizando por se referir à ameaça que paira da parte de interesses econômicos que olham com olhos de lucro para o patrimônio nativo à visa do desenvolvimento sustentável. Ainda segundo o autor supracitado, esta situação é indubitavelmente verdadeira para muitos, senão a maioria, dos grupos indígenas amazônicos (e, pode-se adicionar, grupos caboclos, ribeirinhos) e não tem passado despercebida as companhias farmacêuticas e de produtos da natureza, embora a ética dessa exploração neocolonial seja raramente questionada.

\section{Índices e seus sobrenomes}

a) Índice de capacidade básica

A Social Organization Watch (Organização Social Watch) apresenta uma alternativa não monetária de medir a pobreza e bem-estar, baseada nas capacidades básicas indispensáveis para sobrevivência e a dignidade humana. $O$ índice é calculado com a média de três indicadores: mortalidade de crianças menores de três anos; saúde reprodutiva ou maternoinfantil medido pelo número de partos atendidos; e educação medida com a combinação de matrícula no ensino primário, a proporção de crianças que chegam a quinta série e a taxa de alfabetização dos adultos.

b) Índice do planeta feliz

De acordo com Castells (2012) este índice foi criado pela fundação britânica The News Economics Fundation, cujos elementos indicadores são: esperança de vida ao nascer, satisfação com a vida (Bem Viver subjetivo) e pegada ecológica. Trata de identificar como a dotação e o consumo dos diversos recursos naturais intervêm no bem-estar das pessoas. A mais 
destacada conclusão é de que o país com maior tendência de consumo, não é o que apresenta melhor bem-estar.

c) Índice da felicidade interna

Quanto à felicidade interna Weiner (2009) destaca o Butão, país asiático onde há uma concepção de vida que se adequa ao debate em conceitos que nos leva a construir um arquétipo de Bem Viver.

\section{Bem viver - alternativa ao desenvolvimento}

Não faz muito tempo e vivia-se no Amazonas, uma sensação de tranquilidade, felicidade, bem-estar, segurança, euforia e alegria, progresso e um desenvolvimento rápido e sem fronteiras étnicas ou sociais. Vinham pessoas de outras regiões do país e, predominantemente do Nordeste, norte e interior do estado. Todos tinham em comum criar uma forma de vida em grupo.

Esse tempo se define da seguinte forma em Dom Quixote de la Mancha:

Ditosa idade e afortunados séculos aqueles, a que os antigos puseram o nome de dourados, não porque nesses tempos o ouro (que nesta idade de ferro tanto se estima!) se alcançasse sem fadiga alguma, mas sim porque então se ignoravam as palavras teu e meu! Tudo era comum naquela santa idade; a ninguém era necessário, para alcançar o seu ordinário sustento, mais trabalho que levantar a mão e apanhá-lo das robustas azinheiras, que liberalmente estavam oferecendo o seu doce e sazoado fruto. As claras nascentes e correntes rios ofereciam a todos, com magnífica abundância, as saborosas e transparentes águas (SAAVEDRA, 2015, p. 27).

Ao fazer essa lembrança o autor traz à memória o tempo em que nada era de ninguém, e tudo pertencia a alguém. A cidade pertencia aos urbanos, os rios pertenciam aos ribeirinhos e a floresta pertencia aos índios, aos povos tradicionais. Não havia a conjugação do TER, SER, FAZER. Tudo era comum a todos e não havia necessitados entre si.

O desenvolvimento atroz impele-nos a criar as tribos comunitárias em que cada uma tem seu código de funcionamento e ética. Que muitas vezes se confronta com outras éticas, outros funcionamentos. Segundo Nascimento (2014) a ideia de rede é provocativa quanto à complexidade que se estabelece entre os diversos níveis e atores da sociedade contemporânea.

\section{Horizonte estratégico}

Vivemos crise moral e política no mundo, e não menos importante no Brasil. Crimes ecossociais estão espalhados por toda parte. Crimes contra as mulheres, crianças, jovens, indígenas, povos tradicionais, quilombolas, homens, LGBTI+, refugiados e outros tantos. Verdadeira atrocidade contra toda a humanidade. Não é diferente com o desenvolvimento. As macroeconomias estão avassalando dramaticamente através do sistema capitalista predador, as vidas em sociedades. 
Depois de alguns anos de relativo otimismo no Brasil, infere Acosta (2016) que está cada vez mais evidente que as sociedades do norte e do sul, globais estão irremediavelmente interligadas, muito além de acordos climáticos, que é uma proposta insuficiente para a propositura do Bem Viver no mundo. Mas onde está o projeto estratégico do Bem Viver? Qual o horizonte se apresenta?

$\mathrm{Na}$ atualidade vê-se a proposta de Bem Viver sendo ameaçada por forte influência de três fatores: (I) litisconsorte - uma pessoa que demanda com outra em juízo, figurando no processo como coautor ou corréu; (2) Poder autoritário - a capacidade de deliberar arbitrariamente, agir e mandar, dependendo do contexto, a faculdade de exercer a autoridade, a soberania, o império; (3) Justiça - um conceito abstrato que se refere a um estado ideal ( e não real) de interação social em que há um equilíbrio.

Analisando:

I. Litisconsorte deveria ser como sugere o radical da palavra, um consórcio entre o governo e as sociedades, sem que haja necessidade de demandar juízo (ligado à justiça);

2. Poder autoritário revela imposição, mas deveria estar a serviço da sociedade para sustento do equilíbrio (ligado ao litisconsorte);

3. Justiça apesar de ser abstrata, exerce papel difusor da equidade social, mas acaba sendo chicote, aguilhão, julgo que fere a soberania popular (ligada ao poder autoritário).

Assim, o horizonte para a execução do plano de BEM VIVER está sob judicie de governos desprovidos de articulação em gestão, governos autoritários, governos bairristas, governos cuja meta é governar para fora e não para dentro. Enfim, um horizonte raquítico, com desenvolvimento desnutrido por dentro, porém, robusto por fora.

\section{O viver melhor ou o bem viver?}

$\mathrm{Na}$ ideologia dominante no mundo, viver melhor é desfrutar de uma melhor qualidade de vida que está associada ao Produto Interno Bruto de cada país. Países como os Estados Unidos, Japão, Alemanha e Suécia que possuem os PIB's mais elevados, tendem a ter melhor qualidade de vida. Seria verdadeira a afirmação se essa não fosse uma medida inventada pelo capitalismo para estimular a produção crescente de bens materiais a serem consumidos.

De acordo com Boff (2009) nos últimos anos, dado o crescimento da pobreza e da urbanização favelizada do mundo, a Organização das Nações Unidas (ONU) introduziu a categoria IDH, o “Índice de Desenvolvimento Humano", em que se concentram valores inatacáveis como saúde, educação, igualdade social, cuidado para com a natureza, equidade de gênero e outros. Enriqueceu o 
sentido de "qualidade de vida" que era entendido de forma muito materialista: goza de boa qualidade de vida quem mais e melhor consome.

Boff (2009) contribui ao afirmar que nas tradições indígenas pela América do Sul que ao invés de "viver melhor" se fala em "bem viver". Esta categoria entrou nas constituições da Bolívia e do Equador como o objetivo social a ser perseguido pelo Estado e por toda a sociedade.

O "viver melhor" supõe uma ética do progresso ilimitado e nos incita a uma competição com os outros para criar mais e mais condições para "viver melhor". Entretanto, para que alguns pudessem "viver melhor" milhões têm e tiveram que "viver mal”. É a contradição capitalista.

Contrariamente, o "bem viver" visa a uma ética da suficiência para toda a comunidade e não apenas para o indivíduo. O "bem viver" supõe uma visão holística e integradora do ser humano inserido na grande comunidade terrena que inclui além do ser humano, o ar, a água, os solos, as montanhas, as árvores e os animais; é estar em profunda comunhão com a Pacha Mama (Terra), com as energias do universo e com Deus (BOFF, 2009,sp).

Para o autor a preocupação central não é acumular, parte-se da ideia de que a Mãe Terra nos fornece tudo que precisamos. O trabalho supre o que ela não nos pode dar ou a ajudamos a produzir o suficiente para todos, também para os animais e as plantas. "Bem viver" é estar em permanente harmonia com o todo, celebrando os ritos sagrados que continuamente renovam a conexão cósmica com suas ancestralidades e o divino.

O "bem viver" nos convida a não consumir mais do que o ecossistema pode suportar, a evitar a produção de resíduos que não se pode absorver com segurança e nos incita a reutilizar e reciclar tudo o que for usado. Fazendo assim, um consumo reciclável e consciente.

\section{Considerações finais}

O Desenvolvimento do Bem Viver junto aos povos tradicionais em sua análise, vem carregado com codinomes e sobrenomes para facilitar o entendimento e a dinâmica social em torno do tema. Contudo, a ação de codinominar faz-nos apoiar em um fato interessante nesse estudo: a escalada humana através de uma matriz de percepções das necessidades axiológicas e existenciais, fazendo um cruzamento para identificação de um parâmetro de aceitação do Bem Viver.

Quanto aos índices, seus codinomes retratam a ligação do desenvolvimento com a proposta das necessidades invertendo a lógica de que para viver bem, precisa-se produzir e consumir mais para viver melhor.

A globalização social não acena para um horizonte muito salutar. Muito otimismo criado há pouco tempo se transformou em uma perspectiva de incertezas quanto ao prosseguimento do projeto deixando um vazio de respostas sobre os questionamentos ora apresentados neste trabalho.

Sabe-se ainda, que a vida na terra passa por modificações diárias ao longo de bilhões de anos. Todo dia nascem e morrem pessoas, vegetações e animais. As leis naturais são imutáveis, porém, as 
leis físico-humanas criadas para a regulamentação das convivências essas sofrem alterações em todo canto do planeta numa tentativa de trazer uma relação de bem viver mais saudável, amigável e apaziguador.

Nota-se que há um discurso tecnicamente teórico sobre o desenvolvimento humano. A frustração com o plano de desenvolvimento levou governos e estudiosos a pensarem e criarem parâmetros de mensuração desse espírito de pobreza e mal-estar social. Sobrenomes que em nada mudam o estado paupérrimo que se encontra a humanidade, a natureza e os meios de convivência.

Conservar as áreas protegidas é uma tarefa urgente. Elas compõem o imaginário da natureza primitiva, com suas espécies singulares e seus povos indígenas e populações tradicionais com características únicas e pouco afetadas pela sociedade de consumo.

Qualquer proposta de desenvolvimento deverá considerar a qualidade ambiental, estimulando os investimentos nas áreas mais adequadas e obstando o programa de alto risco, econômico, social e ambiental.

\section{Referências}

ACOSTA, Alberto. O bem viver: uma oportunidade para imaginar outros mundos. Elefante, 2016.

ALCÂNTARA, Liliane Cristine Schlemer; SAMPAIO, Carlos Alberto Cioce. ST 4 Bem

Viver:(de) colonização como processo de resistência das comunidades

indígenas. Anais ENANPUR, v. 17, n. I, 2017.

BOFF, Leonardo. O viver melhor ou o bem viver. Adital-Agência de Informação Frei Tito para a América Latina. Disponível em: $<$ http://www. adital. com. br/site/noticia. asp, 2009. Sem paginação.

CASTELLS, Manuel; CARAÇA, João; CARDOSO, Gustavo (Ed.). Aftermath: The cultures of the economic crisis. Oxford University Press, 2012.

CAVALCANTI, Clóvis (Org.) DESENVOLVIMENTO E NATUREZA: Estudos para uma sociedade sustentável. INPSO/FUNDAJ, Instituto de Pesquisas Sociais, Fundação Joaquim Nabuco, Ministério de Educação, Governo Federal, Recife, Brasil, 1994. p. 262. Disponível em: http://168.96.200.17/ar/libros/brasil/pesqui/cavalcanti.rtf.

CRUZ, Jocielene Gomes da. Organização político-cultural e interculturalidade na gestão dos territórios indígenas para o Bem viver no Rio Negro-AM. Manaus. UFAM, 2015.

DÁVALOS, P. El "Sumak Kawsay" o el "Buen vivir" y las cesuras del desarrollo. Alai, América Latina en Movimiento. Quito. 6, 2008. Disponível em: http://www.alainet.org/es/active/23920 Acesso em 29 mai 2019.

DE SOUSA SANTOS, Boaventura. Descolonizar el saber, reinventar el poder. Ediciones Trilce, 2010.

ILLICH, Iván. Obras reunidas/Collected Works. Fondo de Cultura Económica, 2008. 
LATOUCHE, Serge. Existirá uma vida após o desenvolvimento?. Estudos de Sociologia, v. 2, n. i6, p. 217-230, 2014 .

LANDER, Edgardo et al. (Ed.). A colonialidade do saber: eurocentrismo e ciências sociais: perspectivas latino-americanas. CLACSO, Consejo Latinoamericano de Ciencias Sociales= Conselho Latino-americano de Ciências Sociais, 2005.

KAPP, W. Social costs of private enterprise. Cambridge, Massachusetts: Harvard University Press: 1963.

MAX-NEEF, Manfred A.; ELIZALDE, Antonio; HOPENHAYN, Martín. Desarrollo a escala humana: conceptos, aplicaciones y algunas reflexiones. Icaria Editorial, 1994.

MARTINS, Eduardo. Os pobres e os termos de bem viver: novas formas de controle social no império do Brasil. 2003. 195 f. Dissertação (mestrado) - Universidade Estadual Paulista, Faculdade de Ciências e Letras de Assis, 2003. Disponível em: 〈http://hdl.handle.net/ri449/93133〉

NASCIMENTO, Izaura Rodrigues. Globalização ambiental, organizações não governamentais e redes na Amazônia. Editora Valer. Manaus, 2014.

ONU. Declaração das Nações Unidas sobre os direitos dos povos indígenas. Rio de Janeiro: 2007.

ORGANIZAÇÃO SOCIAL WATCH. Índice de Capacidades Básicas. Disponível em https://www.youtube.com/watch?v=WT78VMLLgig, Acesso em o9 jul 2019.

QUIJANO, Aníbal. Don Quijote y los molinos de viento en América Latina* Aníbal Quijano. De la Teoría Crítica a una crítica plural de la modernidad, p. 123, 2007.

SAAVEDRA, Miguel de Cervantes. Dom Quixote, do local. Editorial Verbum, 2015.

SACHS, Nancy. Ecodesenvolvimento: crescer sem destruir. In: Ecodesenvolvimento: crescer sem destruir. Vértice, 1986.

SANTOS, Cirlene Batista dos. A (re)organização do território e bem viver para os povos indígenas do Alto Rio Negro: da maloca à cidade. 2019. Dissertação (Mestrado em Geografia) - Universidade Federal do Amazonas, Manaus, 2019.

SEN, Amartya. Desenvolvimento como liberdade. Editora Companhia das Letras, 2018.

SOUZA, José Eurico Ramos de. A contribuição do IFAM - Campus São Gabriel da Cachoeira para o desenvolvimento local/regional frente à diversidade étnica e cultural da região do Alto Rio Negro no Amazonas (2007 - 2014). Manaus. UFAM, 2018.

WEINER, Eric; ROCHA, ANDREA. Geografia da Felicidade. Agir Editora, 2009

VANHULST, J.; BELING A. Buen Vivir: emergent discourse within or beyond sustainable development. Elsevier, Ecological Economics Ior, 2014, pp. 54-63.

YAMPARA, S.H. Pachakutt. I-Kandiri en el paytiti [reecuntro entre la búsqueda y retorno a la Armonia originaria], La Paz: ediciones qamañpacha-CADA: 1995. 